\title{
Striving for Normality in a Time of AIDS in Malawi
}

Pauline E. Peters, Peter A. Walker, and Daimon Kambewa

CID Working Paper No. 167

May 2008

(C) Copyright 2008 Pauline E. Peters, Peter A. Walker, Daimon Kambewa, and the President and Fellows of Harvard College

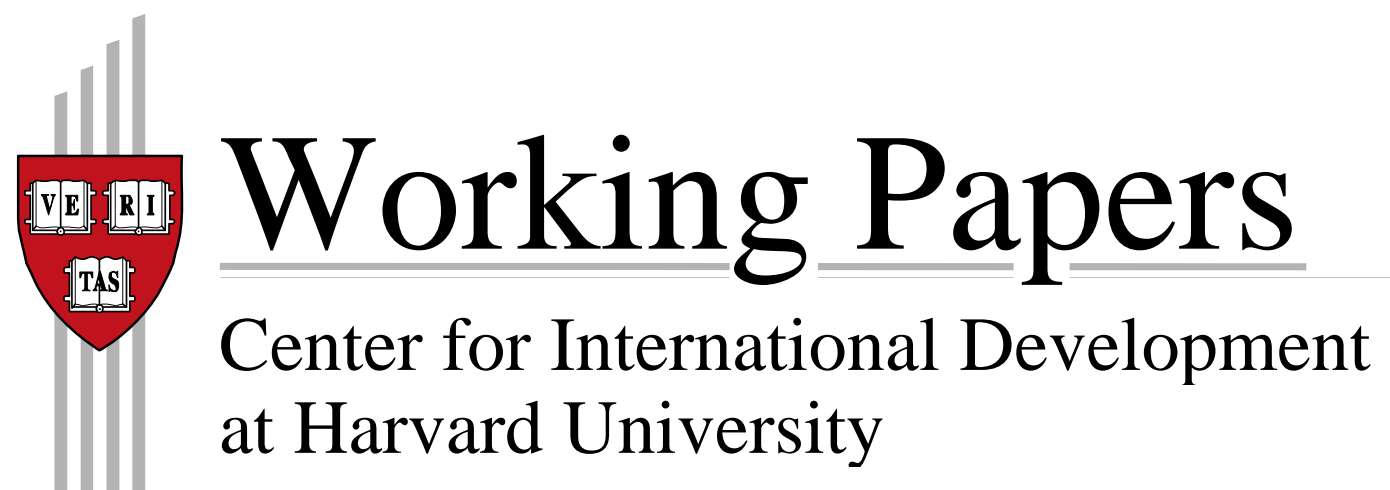




\title{
Striving for Normality in a Time of AIDS in Malawi ${ }^{\dagger}$
}

\author{
PAULINE E. PETERS*, PETER A. WALKER**, DAIMON KAMBEWA*** \\ *Harvard Kennedy School, 79 JFK Street, Cambridge, MA 02138 \\ ** Geography Dept., University of Oregon, Condon Hall, Eugene OR 97403 \\ ***Bunda College of Agriculture, P.O.Box 219, Lilongwe, Malawi
}

Email: pauline_peters@harvard.edu; pwalker@uoregon.edu; dkambewa@hotmail.com

\begin{abstract}
*Acknowledgements. Our deepest thanks go to the families who have been so helpful and hospitable during the years of research. Thanks also to the Centre for Social Research, University of Malawi; our assistants Davie Chimwaza, Francis Chingwalu, Noel Mbuluma, Diana Muwa, Gertrude Songo; data analysts Lucie Heinzerling, Marie Javdani, Ann Laudati, Vishal Gujadhur; and our funders FulbrightHayes, RENEWAL, Kennedy School, University of Oregon.
\end{abstract}

\begin{abstract}
Drawing on a twenty-year study, we examine the effects of HIV-related illness and death on villagers in Malawi during 2006. Contrary to unidimensional images of an AIDS disaster, we found people striving for normality - trying to control the abnormal circumstances of the rising toll of HIV-related illness and death. Just over $40 \%$ of the sample households had experienced at least one death (certainly to likely) related to HIV, but only about $10 \%$ were found to be suffering acute or serious livelihood stress due to HIV deaths. The ability to deal with illness and death depended on households' preexisting characteristics, particularly income level and, critically, on their placement in the extended matrilineal family. But increasing pressures on an already severely stressed population, and failure of the current 'community-based' approach to deliver needed help argue for more concerted efforts to link the HIV epidemic to broader based development.
\end{abstract}

Keywords: HIV/AIDS, household livelihoods, longitudinal analysis, Malawi, Africa, anthropological analysis

JEL Codes: R20, Z1

${ }^{\dagger}$ Accepted for publication in the Journal of Modern Africa Studies 


\section{INTRODUCTION}

The past decade has brought home to people in Malawi, as across Southern Africa, the horror of HIV infection and the resulting diseases of AIDS. ${ }^{\mathrm{i}}$ The character of HIV is now known to be sly, selective, and slow. Most people do not know they are infected till they become chronically ill, most of those infected and dying are adults between eighteen and fifty, and the trajectory of illness is painfully drawn out for many. Personal tragedy is reflected manifold in the wider society, with the multiplied effects resulting in rapid declines in average life span, severe losses of skilled and experienced staff in the full range of professions and industry, fears of undermined agricultural production, and projected failure to reach development goals thought possible before the major impact of the epidemic.

Many have written on the need to situate the disease's effects on individuals and families within wider social, political and economic systems, ${ }^{\text {ii }}$ and to link AIDS more systematically to broader policies geared to national development. Another challenge to understanding and action is that the patterns of infection/illness and of care for the sick are structured by socio-cultural beliefs and practices regarding sexual relations, health and sickness, and responsibility within and between families. Because of this manylayered context, much research has shown 'considerable variation in effects on household livelihoods' (Murphy et al 2005: 265). The 'long-wave’ character and the variability of patterns within and across countries have led to a call for 'more longitudinal studies that capture the local dynamics of impact and response in different situations' (Gillespie and Kadiyala 2006: 81). 
In this paper, we draw on a twenty-year study in the southern district of Zomba in Malawi’s Shire Highlands to examine how people are trying to live under the onslaught of HIV-related illness and death. ${ }^{\text {iii }}$ The answer is mixed. Here, we focus on the following points: the defining character of response was of people striving to achieve a degree of normality, and not of pervasive defeatism or fatalism; while just over $40 \%$ of the sample households had experienced at least one death certainly to likely related to HIV, and there has been a marked decrease in the proportion of young adults and infants in the sample over twenty years, only about $10 \%$ were found to be suffering acute or serious livelihood stress due to AIDS deaths; the ability to deal with illness and death depended on households' preexisting characteristics, particularly income and, critically, on their placement in the extended matrilineal family; but increasing pressures on severely constrained resources, and failure of the current 'community-based' approach to deliver needed help argue for more concerted effort to link the HIV epidemic to broader based development strategies.

We do not wish to underestimate the toll of the HIV epidemic: the stress of severe illness and tragedy of death among prime age adults are palpable. But our findings caution against some of the more gloomy accounts and suggest that there is no pervasive family 'breakdown', that few orphans (none in our sample) are abandoned, and that few households dissolve, rather members regroup within the extended family network. Many families, however, are being severely strained and deserve more systematic help. 


\section{STRIVING FOR NORMALITY}

People in Malawi, as in neighbouring countries, are often described as being in a state of 'denial' with regard to the HIV epidemic. The most usual sense in which people are charged with denial concerns the dominant tendency to refuse to name AIDS in cases of illness and death. There are several reasons to be dissatisfied with this assessment. First, naming AIDS is more selective in Malawi. People do use the term edzi (a Malawianised form of the English AIDS) when referring in general to the current surge of illnesses and deaths in the country. Whereas in 1986 in the research villages, there was absolutely no talk of AIDS, and in 1990 only the beginnings of a realization about a 'new disease', by the late 1990s and even more by 2006, adults knew a great deal about AIDS. But extremely few use the term edzi when referring to the illness and death of someone they know well, particularly relatives. More use the more common 'roundabout' terms for AIDS $^{\text {iv }}$ in describing deaths of others but again, far fewer use even these indirect terms to describe the illness and deaths of close relatives. At most funerals, the public statements about the deceased carefully avoid any reference to AIDS, even though some of those attending may whisper suspicions. This practice follows the well-established tradition of not speaking ill of the recently deceased. The common association of AIDS with inappropriate sexual behaviour results in this avoidance (see below).

A more fundamental objection to describing the situation as one of denial is that it is superficial. Fassin, for example, says that 'denial, in its deepest sense, signifies the intolerable’ (2007: 120). In such stressful times, the term 'denial' glosses over the ways in which people are torn between acknowledging the way in which the disease has felled them, and refusing to recognise the 'unbearable' knowledge (ibid.). Recently, Alex de 
Waal used the concept of 'normalization' to refer to the ways in which people 'adjust... reality to take account of the miseries of AIDS' (2006:18). Much of what the Zomba villagers do can be seen as striving for normality. Rather than sunk in denial, they are better seen as trying to control the abnormal circumstances of the rising toll of HIVrelated illness and death, making huge efforts to channel them into the normal and normative ways of their society. A very similar conclusion has been drawn by Chimwaza and Watkins about care-givers to people sick with AIDS in Malawi when they say that the 'reluctance' shown by many in speaking openly of AIDS 'is not a denial but something more existential... [in that the caregivers] turn away from acknowledging, even to themselves, that their child, their mother, or their aunt will not survive despite their devoted care’ (2004: 805).

Such efforts are seen in the ways in which the matrilineal family and its constituent households seek to deal with the increases in illness, death and orphans, by moving the sick and orphans around the constituent households. Enormous efforts are made to recreate a 'normal' family. One example among many is Mai C. Her divorced elder sister, Anna, died in 2004. Mai C took in four of the children, the two youngest going to another 'sister' (mother's sister’s daughter) nearby. In addition, Mai C was looking after two other teenage boys, orphaned by the death of another sister. By 2006, two of Anna's sons had married, though one continued to live in Mai C's compound with his wife. During 2006, her younger brother who was very sick came to be looked after by her, ${ }^{\mathrm{v}}$ a decision taken by herself and her two other older brothers, one of whom was welloff and provided for most of the medical costs. The sick brother had all the symptoms of 
AIDS though Mai C. mentioned only meningitis. In no conversation did Mai C suggest that her expanded and changing household was unusual.

Another major dimension of the process of 'normalization' is to assess cause (why this person died). People draw on both preexisting sets of explanatory principles and on newer suggestions emanating from many sources, including churches, government, medical experts, and media discussions. There has been a veritable blitz of information about HIV/AIDS and most people associate the epidemic with too many sexual encounters ${ }^{\mathrm{vi}}$, but there are also competing theories about the epidemic and about any particular person's illness and death.

People in the research site do not distinguish linguistically between HIV and AIDS; the former is hardly referred to at all, while the many indirect terms used for edzi all refer to illnesses. The partial exception is that some people, including some local healers, refer to tizirombo, 'little animals' or organisms in the blood which they see as causing the illness. ${ }^{\text {vii }}$ Many knew that a person could be infected with the HIV virus but appear perfectly well, ${ }^{\text {viii }}$ but most attention is paid to overt illnesses attributable to AIDS.

The sexual transmission of HIV is well known in the area and is the overwhelming focus of public discourse. While the level of voluntary testing is still extremely low, there have been increases in the availability of testing in the rural areas; some people are definitely paying more attention to the known behaviour of their spouses, friends, and neighbours and making changes in their own practices, such as some youngsters 'holding their hearts' (that is, not engaging in sex too early or too often), some adults holding each other to stricter standards than before (a woman sending off her husband because she learned he was taking lovers in his trips to town, a chief who had 
himself and his new wife tested before marriage, a man who, suspecting his wife of taking lovers on her trips to market, got himself tested).

These echo the detailed information emerging from the University of Pennsylvania study sites from the late 1990s to the present (Watkins 2004, Smith and Watkins 2005). Again, this is not to say that there is radical transformation in the sexual and related practices of Malawian villagers in Zomba. To expect such would be to misrepresent the capacity of people living in severely stressed situations to 'choose' to completely change well-established practices. For example, as we have found in the sample area in earlier years, a woman with a decent amount of land can attract a husband more easily than others, and everyone knows that two adults can produce more crops and more income from such land than can one; so it is not surprising that widows, especially those under about fifty, tend to remarry quickly. ${ }^{\text {ix }}$ Many people continue to have multiple partners, some sequentially (as in remarrying after death of a spouse or after divorce), some simultaneously. Multiple partnering is not confined to the rural areas and may even be more common in towns and among those with higher incomes. ${ }^{\mathrm{x}}$

For some, the sexual transmission of HIV produces blame, such as the mother who told her dying daughter that she had brought the illness on herself by her careless behaviour, or the mother who blamed the girl-friend of her deceased son for passing an illness to him. Some repeat the common stereotypes currently deployed in discussion about AIDS such as the claim that 'poverty' leads women to sell sex, or a tendency to blame women for affairs outside marriage even though such love relationships (chibwenzi) are common throughout Malawi and reportedly more indulged in by men than women. As Fassin points out, the HIV epidemic uncovers 'preexisting stigmas' and 
prejudices, so revealing as much or more about the society as about the disease itself (2007: 32).

Other interpretations given to the rise in illness and deaths resemble those identified by other researchers in Malawi and in neighbouring countries. These are: AIDS is a more virulent form of a well-known illness (kanyera) caused by infringing certain sexual rules ${ }^{\mathrm{xi}}$; the illnesses some define as AIDS are sent by malevolent people through witchcraft; AIDS is a disease that has been deliberately inflicted on Malawians through infected condoms, family planning pills and injections. The agents assumed to be behind the purposive infliction of AIDS are God (who sent it as a punishment for immoral or sinful behaviour), as well as Whites (Europeans or Americans) and the government of Malawi (who distribute infected condoms and other contraceptives in order to reduce the population) ${ }^{\text {xii }}$ The agents assumed to be behind the bewitching of people are seen to have a wide range of motives, depending on the relationship between them and their victims, though they generally turn on envy and jealousy.

People often hold several different ideas at once or at different times or for different circumstances. Well before the era of HIV, the interpretation of a person's illness has often varied according to circumstances. Depending on the trajectory of the illness, the diagnosis of what is causing the illness may change over time, particularly if the illness fails to respond to treatment and the patient fails to improve. The effect of AIDS has been to intensify this pattern of multiple interpretations that draw on a repertoire of available and changing ideas. HIV infection has produced an unprecedented explosion of serious (chronic) illness in the very segment of population normally most healthy (people from the late teens to around 50), a situation which, along with the 
incurable nature of 'this new disease' is deeply worrying. It is no wonder, then, that people are involved in an agonizing search for explanations on which they can base their own actions.

\section{THE PAST IN THE PRESENT: 1986-2006}

The past twenty years in Malawi have seen palpable change: a shift from the highly controlled, autocratic regime of Dr Banda to a 'multi-party' regime in 1994 and subsequent political volatility; structural adjustment, increased economic instability due to both national and international conditions, and deepening dependence on foreign aid; and periodic droughts and floods suggesting an increase in climatic volatility with severe effects for agriculture. Within this overall context, the study households have been marked by increasing heterogeneity and inequality over the period (see Peters 2006). The average landholding of study households has changed very little over the period, ${ }^{\text {xiii }}$ but the deepening inequality can be attributed to declining overall returns to agricultural production for the majority of the smallholder cultivators after a boom in burley tobacco earnings in the early to mid 1990s, and to similar difficulties in earning money off-farm whether in the formal wage sector or, for most, in the localised, 'informal' activities of casual labour, and small-scale business.

The critical changes for the study households between 1986 and 1997 were the effects of structural adjustment and market liberalization of the late 1980s into the early 1990s, including the opening of burley tobacco production to smallholders (previously limited to estates) and the opportunity of selling it on the Auction Floors at world prices. Average sample household income rose by just under 60\% between 1986 and 1997, due 
largely to the sharp rise in burley tobacco production. However, the aggregate sample figures masked an increasing gap between the poorest and the richest: in 1986 the top quartile households had incomes four times bigger than the bottom quartile, a ratio that increased to eleven times by 1997, remaining much the same, at 10:1, in 2006.

All households have followed diversified livelihood strategies throughout the period but the income shifts mirror changes in these strategies. In 1986, the sample as a whole earned approximately 30\% of household income from the value of retained ownproduced maize (the staple food), 30\% from sales of agricultural produce, $24 \%$ from nonfarm sources (wages, small business, etc), and 15\% from transfers (from absent working husbands and adult children). The mix of activities has not changed over the entire period but the ratio has altered. Already in 1986, the households in the poorest quartile earned more from off-farm sources and less from sale of agricultural produce than the better-off. This pattern intensified by 1997. By then, the most important source of cash income for the richest quartile households came from sales of burley tobacco, with important contributions from sales of maize, legumes and vegetables. Most of these better-off households also continued to produce all the staple maize they needed as well as surplus maize, part of which they sold, part of which they kept to hire casual labourers in the peak cultivation season.

In contrast, the poorest households were finding it difficult to obtain as much staple maize as they needed and so reduced their already small sales of agricultural produce while increasing the proportion of earnings (in kind as well as cash) from casual labour for their better-off neighbours and small estates in the area. Their falling further and further behind the gains of the better-off households and the increasing proportion of 
their meagre expenditures spent on obtaining basic foodstuffs revealed the increasing pressure they were under by the end of the 1990s. Some were increasingly caught in the vicious cycle whereby they were able to allocate less labour and other inputs to their crops because of lack of cash and their need to work for others in the deficit food season (which is also the peak cultivation season), ${ }^{\mathrm{xiv}}$ thereby reducing their own production.

While a major factor in increased socio-economic differentiation for the sample has been burley tobacco, it is not the only one (and for many areas of Malawi it is inconsequential). Other contributing factors are the reduction in sources of institutional credit for fertiliser and seeds, the increasing importance of access to sufficient land in face of the volatility of crop prices in less regulated markets, the great reduction in options for migrant labour, and a flood of people into petty trading with low returns (cf. Dorward and Kydd 2004: 346, Ellis et al., 2003).

The summarised data on income shifts present a flattened picture of people's lives, whereas the study household members were active players throughout this period of considerable political economic change. Studying and living among the study families, we were struck by how hard most people worked, whether in their fields or elsewhere, and how quick most were to take up new options presented them. As new crops and new markets appeared to open, so many took up the challenge of responding by growing and selling the crops. New varieties of maize and pigeon peas, new markets for chili peppers, sunflower, sweet potatoes and cassava all led farmers to adapt and modify their planting patterns. Not all these 'opportunities' proved sustainable - the boom in chili peppers of the early 1990s collapsed as supply outran the demand, sunflower prices oscillated wildly between good and bad, and some of the organizations of producers set up to take 
advantage of bulk selling fell apart. Some of the best farmers in the sample proved to be true experimenters, testing out different seeds and different techniques to see what worked best. Many kept to tried and true systems (of plant intercropping and plant sequencing, types of seeds, and so on), and, inevitably, some were just poor farmers and equally inept in efforts to run small businesses. Overall, many of the sample households deployed considerable effort, discipline, and judgment in negotiating these difficult years. Most remained poor and continued to struggle to make a living, some became even poorer, and a minority benefited.

Throughout these years, too, we learned about the cultural and moral principles according to which people judged their own and others' lives. First, there is a deep-lying and usually unarticulated value attached to the matrilineal system of kinship (a child belongs to his mother's lineage), inheritance (the main heirs and successors of a man are his sisters' children, and daughters not sons inherit matrilineal land), and the matrilocal pattern of residence (whereby on marriage a husband moves to the village/compound of his wife). ${ }^{\mathrm{xv}}$ As described in detail elsewhere, people in this area have maintained these patterns 'against all odds', sloughing off the prejudices against matriliny by missionaries, colonial officers, and others (Peters 1997, 2002). Documentation of study households in the agriculturally vibrant research area over the twenty year period provides no support to the still present stereotype that men living and working on their wives' land do not have the 'incentive' to invest their efforts in that land. The matrilineal mode of land transfer also provides considerable flexibility to people who juggle diverse livelihoods. For example, a sister who obtains a job in town will cede her field to another relative but will have it returned or replaced when she returns; or a son returning to his natal home 
between marriages will be loaned a field by his mother or sister. The way in which people define kinship and inheritance and the proper mode of post-marital residence is a critical foundation to understanding their lives and their efforts to construct livelihoods. These understandings shape the patterns of inheritance, the disposition of responsibility for land, children, and property, and the course of defining and treating misfortune, including illness.

This brief sketch of the socio-cultural and economic circumstances of the Zomba sample households up to the late 1990s now allows us to ask how these circumstances influenced the ways in which rural people in Zomba district sought to live under the onslaught of HIV/AIDS, as perceived in 2006.

\section{HIV-RELATED DEATHS AND PATTERNS OF STRESS}

The study findings echo those that document considerable heterogeneity across households in their ability to deal with the HIV epidemic, and a very low rate of household dissolution (Mather et al. 2004). This is partly due to preexisting levels of resources, with the better-off more able to support the increased costs of care and of death, and partly to the fact that households are not solitary units but part of extended matrilineal families that adapt and reshape themselves in relation to loss and crisis. About a quarter of adult deaths reportedly attributable to HIV/AIDS were of the principal couple - the key woman and husband. The immediate impact of such deaths is often acute, with loss of cultivation time and hence of harvests, loss of other sources of income, and rising costs, financial and other, in caring for seriously sick people and in organizing funerals. 
However, in the large majority of cases, the households did not dissolve and were maintained by the surviving wives who often remarried within a few years, or were taken over by adult daughters, sister's daughters and a few sons. Orphans were shared out among relatives and land was taken over by heirs (daughters, sisters or sisters' daughters). We learned of no cases of 'land-grabbing'. Rather, the land of deceased persons followed the customary routes to appropriate heirs. Widows of men known or suspected of dying of AIDS were treated no differently from other widows, the same being true of widowers. There was certainly ambivalence and tension - what commentators refer to as 'stigma' - around deaths attributable to AIDS, as mentioned above, but the study found no evidence that 'HIV widows' faced special discrimination. Doubtless, the strongly matrilineal and matrilocal practices of the area provide a key reason for this lack of special suspicion towards widows, who are normally surrounded by matrilineal relatives. In the minority of cases where wives were living in their husbands' villages, after the death of a husband, the widow returned to her own natal village with her children. Such households thus 'disappeared' from our sample, but are likely to have followed similar paths as the sample matrilocal households.

The most obvious change in the sample was the shift in age distribution between 1986 and 2006 (see Figures 1-2). The samples are small for demographic data, but the decline in numbers of babies and infants and of adults between twenty and forty years of age can only be explained by the deaths from AIDS of young adults and of babies, presumably through infection by their mothers.

It has been more difficult to know with certainty whether or not a household has experienced a death attributable to HIV. Testing was not an option for the research. Thus, 
we had to rely on reports by sample households on deaths. ${ }^{\text {xvi }}$ Since most people in the sample area do not care to talk of the dead, it is difficult for outsiders to pose questions about the number and causes of deaths. It has become even more difficult with the onset of HIV and the rarity with which family members attribute a death to AIDS. The information we have on deaths and their causes has been collected over the entire twentyyear period of study, and not only in 2006. The main source of information has been the 'updates' section on the periodic ${ }^{\text {xvi }}$ household membership surveys which recorded members' deaths, sometimes with a listed cause or, more usually, a description of symptoms, with supplementary information obtained from neighbours and others. Despite our efforts, many deaths that occurred prior to 2006 have too little or no information on which to base an assessment of the cause of death.

With these caveats in mind, we found that of the 174 households who had been in the sample in 1986 and in 2006, 18\% had adult deaths due 'certainly to almost certainly' to HIV, $21 \%$ had deaths 'very likely' due to HIV, and a further $10 \%$ were 'likely' due to HIV. Evidence for the first category of deaths attributed to HIV includes first, actual statements by family or other closely connected families using the various terms for HIV; and second, sufficiently detailed descriptions of the typical sequence of symptoms and illness attributable to the disease. Evidence for the second category 'very likely due to HIV' is based on descriptions of symptoms and length of illness, etc., but at a lesser level of detail. The category 'likely due to HIV' had an even lesser level of detail. The proportion of households who had a death about which there was no or very little information was $30 \%$, and $40 \%$ of households had one or more deaths not attributable to HIV $^{\text {xviii }}$. Because some households had deaths placed in more than one category, the 
percentages overlap. But overall, $43 \%$ of the 174 core households had at least one death categorised in one or more of the three HIV categories. ${ }^{\text {xix }}$ And $28 \%$ of households had no adult deaths at all. Before presenting ethnographic detail on these families, we will present some quantitative results.

\section{The effects of HIV-related illness and deaths}

The two main variables used in the quantitative analysis to get at the effects of the HIV epidemic were households with a certain to likely HIV-related death, and households caring for one or more orphans (29\% had one or more orphans present in 2006). As discussed below, ethnographic analysis shows that households with a currently very sick AIDS patient and those experiencing a recent HIV-related death definitely lost income and sometimes assets. Cultivation was reduced because of sickness and of caring for the sick, so reducing harvests, food stores, and income from sold crops. Other income strategies (from temporary labouring to small-scale business) had also to be curtailed with consequent losses in income. The higher costs for health care and medicines, for transporting the patient to health providers, and for 'special' food desired by the sick all added to the economic stress. However, the sample data on expenditures showed no significant statistical differences between households who had had HIV-related deaths and those who did not. This lack of difference is probably due to the fact that, as discussed below, most households adapt to the effects of HIV-related illness and death over time. Those households, so far in the minority, who continue to be severely stressed economically are mainly those who started off very poor in assets and income opportunities and who have high levels of added burdens as a result of HIV. 
The same reason - adaptation over time to the losses - likely applies to the lack of significantly lower averages in households who have had an HIV death within the past decade compared with others in terms of landholding, harvest, food stores, or whether or not they had received subsidised fertilizer. In fact, households with an HIV death harvested very slightly more per capita than others (188 kg cf. $181 \mathrm{~kg}$ ), and sold less (42\% cf. 52\%). There were some small differences in the expenditure shares households with HIV-related deaths had slightly higher shares than others for medical expenses (3\% cf. $1.9 \%$ ), and slightly less on education (1.8\% cf. $2.4 \%)$, which are intuitively reasonable but not statistically significant. The slightly higher expenditure share on health costs might be driven by those households who had had a severely ill person during the survey year 2006. The slightly lower share spent on education may also be more driven by those whose health costs went up and whose income went down in 2006. But if it typifies more households with an HIV death in the past, then the implications are serious, in that it may portend a vicious cycle in which young people, especially girls, may not only lose education but, in being thrust into early marriage and income-earning, will be at more risk. Ethnographic analysis revealed cases where the teenage daughters of parents who died of AIDS dropped out of school to first help care for their parents (almost always with mother's relatives) and then to run the household themselves. Countering this trend of potential decline is the set of households where the teenaged to adult children inherited more land than normally would have been possible without the deaths of parents and/or older siblings, so obtaining one of the most important assets in the region. 
The most significant relationship was the negative effect on burley growing: households who had had an HIV death were significantly less likely to grow burley tobacco as shown in a regression $(\mathrm{p}<0.01)$. Similarly, the earnings from burley tobacco by households who have had an HIV-related death are, on average, less than a third of those of other growers. This suggests the unsurprising explanation that households who have suffered an HIV-related death find the intensive labour and inputs required by burley tobacco to be beyond their capacity. Burley tobacco is such a demanding crop for households, which always also grow maize and other food crops, that it requires both a husband and wife to be full-time farmers if it is to be grown on any scale. The only exceptions are the very tiny number of people, including a few women, who have sufficient assets and income that they are able to employ labourers. In addition to the labour demands, the fact that the price levels for burley tobacco, even on the Auction Floors, have gone down has been a major disincentive to all households, ${ }^{\mathrm{xx}}$ including those who have lost income through HIV-related illness and death. Apart from the case of burley tobacco, there had been no major shifts in crop production attributable to HIV. ${ }^{\mathrm{xxi}}$

Insofar as the households who were caring for orphans during 2006 are concerned, they had slightly lower average expenditures than others (K2390 cf. K2800 per capita) though the difference is not statistically significant. A comparison of the expenditure shares shows them spending a slightly higher share on maize than those without orphans (17\% cf. $14 \%)$, a very slightly higher share on education (2.9\% cf. $1.8 \%$ ), and not much difference on health (2.2\% cf. 2.5\%). These would suggest part of the cost of increased dependency. While these households caring for orphans do not differ significantly from others regarding the size of land, food stores, or receiving 
subsidised fertiliser, they reaped a smaller harvest (171 kg per capita cf. 189 kg pc), despite spending a higher expenditure share (12.3\% cf. 9.9\%) on fertiliser, and slightly fewer sold maize (45\% cf. 48\%). The negative effect of orphans on harvest is slightly less significant than a similar regression showing the negative effect of dependants on harvest so probably is more a reflection of the effect of dependants on per capita harvest rather than of orphans per se. Nevertheless, these results do suggest the increased pressures, on average, on households where orphans had increased their dependency ratio.

The anthropometry survey showed no significant differences between children living in households who had experienced an HIV death and others. Only four of the children (aged under six) measured were orphans and their average scores were slightly better than those of the rest of the children, though the small number obviously excludes any statistical significance. The improvement in anthropometric measures since the 1990s (though the poorest quartile's children continue to have lower Z-scores) is counterintuitive to the information on persistent poverty and the effects of the HIV epidemic. ${ }^{\text {xii }}$ Sadly, it is probably the case that the infected children die rather quickly so removing them from the children being measured. The age distribution charts described earlier also show the children who have 'disappeared'. Just as a stunted population, which continues to typify Malawi, is essentially a population of survivors, so it would seem that the improvement in anthropometric scores for young children obscures the many who have not survived the HIV epidemic. 


\section{Variable patterns of stress}

A close analysis of the households who experienced at least one death attributable (certainly, very likely or likely) to HIV/AIDS fairly recently (from 1999 to 2006) reveals the following. Four of the fifty-seven households (7\%, or $2 \%$ of the total sample) were suffering 'acute' distress, defined as severe livelihood stress with very low income, food supplies and other assets so that they were unable to achieve what they could before the deaths. ${ }^{\text {xiii }}$ Thirteen (23\%, or $7.5 \%$ of the total sample) had 'serious stress' - shortages of income, food supplies and help that made it more difficult to achieve their needs than before the deaths. Some of these appeared to be already moving into the third category an 'increased burden with some stress', understood as households finding it more difficult than hitherto to provide food and other needs for their members: eleven households fell into this category -- $19 \%$, which is $6 \%$ of the total sample. The remainder (twenty-nine households or $51 \%$ of these cases, and $17 \%$ of the total sample) have experienced negative effects but either these have been relatively short-lived or the households are able to absorb the burdens, due to their high income/asset level, the support from their family, and/or to the relatively light burden of added responsibility.

Close scrutiny of these households reveals that it is essential to take the time span into account when trying to assess effects. Examination of the affected households shows that the most acute signs of stress are in the period of severe illness and death, and for many cases, this seems to mean between a few months and a year. ${ }^{\text {xxiv }}$ The strain, apart from grief, include the time given to caring for the sick at the cost of one's own activities in the fields and other income-earning activities; money needed to obtain medicines and care, both from 'traditional' healers and from clinics or hospitals; provision of 
appropriate foods to the sick; costs associated with transporting the patients to and from health care centres; and, after death, the costs in resources and time, of funerals. ${ }^{\mathrm{xxv}}$ After the death, the duration of distress depends on prior assets and/or a highly supportive family and/or a lesser burden of dependency resulting from the HIV death.

All four households experiencing 'acute economic stress' have either dropped to or remained in the lowest twenty-five percent of households in terms of income. Two have been poor and struggling to achieve a living since 1986, and the third was doing slightly better, largely because of a son's tobacco income, in previous years. The fourth was more prosperous but has dropped precipitously down the income ladder from the inroads of HIV; this last case is also the one with the most recent impact (see Case 1).

Case 1. Abiti $\mathrm{N}$ was the only person in the entire sample to be open about her HIV status. The marriage was polygynous, Che $\mathrm{M}$, the husband, dividing his time between both wives (the other wife lived in a different village) before his death in November 2006. He gained his income from retailing chickens and vegetables though his increasingly severe illnesses, including TB, greatly decreased his income in the past few years. Abiti $\mathrm{N}$ did most of the farming and, despite her own increasing illness, was found struggling with the cultivation and harvest between January and August of 2006. She became progressively more ill and finally died in August, 2007. In terms of income, the household was in the bottom quartile in 1986, in the top quartile in 1990 and 1997, but dropped to the lowest income quartile in 2006. In 1986, Abiti N was divorced with children by at least two different partners and she was living with her elderly parents. By 1990, she had remarried Che M, a Muslim man, the man she was still married to in 2006. Her mother died in 1998 and Abiti N became the key woman. Her father died in early 2005. Both she and her husband had been sick for a few years before they were diagnosed with TB first and then HIV in 2005. The slow decline accelerated between 2005 and 2006 with cash income reduced, costs for medicines and travel to health centres increased, and food production cut. In addition, her three sons (from Che M) and her daughter from a previous partner were losing school in having to help their parents. The sons did not seem keen on school but the daughter was in a high class in secondary school and wanted to continue. However, her mother struggled to pay the fees and she had to manage everything as her mother became increasingly incapacitated. The benefits of 
earlier, more prosperous years are clear: Abiti N's eldest son had completed secondary school and was married, farming in his wife's village, and her elder daughter had also completed secondary school and had a job in a telephone bureau in the capital Lilongwe. After the death of Abiti $\mathrm{N}$ in August 2007, her sister who lives nearby was to become the guardian of the remaining children. That household (not in the sample) is not particularly well-off, so the prospects for the orphans' continuing education seem slim at present.

Of the 13 households ( $7.5 \%$ of the sample) who can be seen to have 'serious economic strain' as a result of an HIV death, four (31\%) are in the lowest expenditure quartile, two (15\%) are in quartile 2, six (46\%) in the third quartile, and one in the top, fourth, quartile (8\%). Two thirds of the households in the third quartile may be shifting towards the category of 'some' strain. As in the group of acute distress, a majority of this set of households (77\%) care for HIV orphans. Of the four households in the poorest quartile, one is of a couple in their late seventies or early eighties whose only daughter died in 1991 of TB (possibly HIV-related) and the grandson who had been helping them died in 2005, likely from AIDS. They appeared to receive no systematic help from other grandchildren or relatives, the only sample household to be neglected in this way. Another household is headed by an elderly widow whose daughter died in 2001, leaving four orphans. This and the (non-HIV) death of her husband in 1996 had led to a drop in income. However, in 2006 she was supported largely by a divorced daughter with whom she lives, and other help came from other married daughters and grand-daughters living around them. The family is not short of land. A third household is headed by a woman in her fifties who took over from her elderly mother who died sometime after 1997. She has lost a daughter and a sister to HIV-related illness and is caring for two teenaged grandchildren who are in school and whose mothers are living elsewhere. Some of her 
other sisters' adult daughters, some orphaned, live around her. She has a tiny amount of land and is able to generate a very low income and standard of living, a circumstance that has typified this family ever since 1986. The fourth household is headed by a Mai K, a woman who has been in the lowest income group except for a short time around 1990 when she was married to a successful fish trader. They divorced and by 2006 she was married to a man who was seriously ill throughout the year with what everyone except himself and his wife said was AIDS. He died shortly after we completed our study. Still vigorous and in her late forties, Mai $\mathrm{K}$ is able to care for the three orphaned children of her daughter who died in childbirth in 2000 (possibly of HIV-related causes), but this responsibility and the care for her husband were pressing hard on her. The eldest of the grandchildren, a girl of 17, seemed to be dropping out of school during 2006.

The eight households in this category of serious strain who are in the middle fifty percent of income all had suffered material costs during the illness and death of their relatives and they were dealing with the extra responsibility of orphans, but they were managing largely through the help of adult children, especially daughters, and in one case help from a mother's brother. The only household in the top quartile in this 'serious stress' category is essentially living off its past (see Case 2).

Case 2: In 1986, the husband was a foreman in a South African mine, sending money home to his wife who was South African and living in her husband's village. By 1990, the man had returned and quickly became an active and successful farmer of maize and burley tobacco, the chairman of the biggest burley tobacco club in his village, and he was well connected to the local elite (better off families, local government officers, and prominent traders). In 1997, he was not doing as well as in the past but still better than the average. In fact, he was already sickening and by 2005-6, he was chronically ill. Their standard of living had fallen considerably, he was unable to cultivate much, and the burden of responsibility for the family fell on the wife's income from her business as a herbalist and diviner in local markets. In fact, information given us by 
other villagers revealed that the husband had taken a large loan on behalf of a committee he'd set up to run certain small businesses, but that he was using the money for his own expenses since he had none from tobacco and had run out of maize. In addition, he was accused by a friend of stealing maize that the friend had temporarily stored in his compound. Although the family remained in the top expenditure quartile in 2006, it was built on debt and, in fact, theft. The husband died in December 2006 after suffering two severe strokes. He was not taken to the hospital, his wife treated him with herbs, and some people around said that he had been bewitched by the friend whose maize he had stolen.

In the category of 'increased burden and some economic stress', just under two thirds (7) of the households are in the bottom quartile and the rest (4) are in the second (next to bottom) quartile. Four of the seven in the bottom quartile have dropped slightly (from the second quartile) between 1997 and 2006, and two have remained at the bottom. Four of the households are headed by divorced or widowed women who have orphans to care for but who, though in a low income group, receive considerable help from adult children, who live in or near their compounds. Three households are of elderly couples who have a few orphans to care for, others having grown and left in marriage, and who are helped by adult children. Two are middle-aged couples who are not well off but managing, one with orphans, the other with none from the recent death (in 2006) of their eldest daughter. Finally, two are households where a young adult married daughter has taken over the household on the death of her mother (and in one case of both mother and father); both have good marriages and seem likely to improve their income status (assuming they do not contract HIV).

The final category of 'minor economic stress and overcoming stress' is of households who have experienced at least one HIV-related death during the previous six or so years but either the ill effect has been relatively short-lived or they are able to 
absorb the burdens. Two characteristics stand out for the group as a whole: First, unlike the households described above in the three other categories, a small minority (14\%) has orphans to take care of. ${ }^{\text {xxvi }}$ Second, most are in the upper income quartiles (41\% in the top, $24 \%$ in the third) with $17 \%$ each being in the bottom two quartiles. Overall, reasons for these households seeming to manage the effects of an HIV-related death include: a lower level of dependency; an income level that has allowed them to absorb the material costs of illness and death; in cases of households in the bottom two quartiles, they form part of families where the burden has been shared; for both the top quartiles and the lower quartiles, the clear importance of help from family members working in town; and in a minority of cases, the deceased person was not a household member but a relative (of the key woman) who came for care when s/he was sick and dying.

\section{HIV-death of a key woman and/or husband}

There were twenty-three cases reported of (certain to likely) HIV-related deaths of key adults. All except one of these died between 1997 and 2006. A close analysis of these households shows that nine of them are now headed by second generation adults (mostly daughters, a few sons, and two sister's daughters) who have married and who have been able to manage the losses due to the deaths. Two other households where the husband died have dropped in income terms but the surviving wives are helped by surrounding matrilineal kin and are not short of land. Eight households have dissolved, seven of them on the death of the husband. Six of these were households where the wife was living in her husband's village, ${ }^{\text {xxvii }}$ and the surviving wife and children went home to the wife's natal family after the ritual dissolution of the marriage. Hence, though they constitute 'dissolved' households for the sample, they very likely were reabsorbed by the 
wife's family. If these patrilocal households are excluded, only two out of seventeen households $(12 \%$, or $1 \%$ of the total sample) dissolved. The eighth household was of a divorced woman living alone with a daughter who, on her mother's death, went to live with her mother's sister in the same village. Three of these 23 households were suffering stress during 2006 and are described above in the section on 'acute stress'. Of the entire group, the key women in three households (two daughters in the second generation category and one sister) had ended up with more land than they would normally have had, because of the deaths of parents and siblings.

\section{THE CRITICAL ROLE OF THE EXTENDED MATRILINEAL FAMILY}

A central conclusion of the Zomba research is that the matrilineal family is doing a remarkable job of providing support to bereaved households. Mobilizing the wider family stems some of the consequences of HIV illness and death. While a few households dissolved in the wake of HIV-related deaths, the children, assets and land were absorbed into other, related households. No young children (those under fifteen) were living alone. As described above, some households were suffering acute economic stress after HIVrelated deaths but they were in the minority, and most affected households had managed, with the help of matrilineal relatives, to take on extra burdens and responsibilities and to weather the difficulties.

The under-researched importance of the extended family has been pointed out by others - by Mtika (2001) for Malawi, and for Zimbabwe by Grant and Palmiere, who conclude that, 'The extended family as a safety net is still by far the most effective community response to the AIDS crisis' (2003: 233). 
The relative silence about the extended family probably derives from the dominant methods employed in research. In virtually all surveys and in most other investigations, the 'household' is the sole unit of analysis; it is also the unit used in all the quantitative data deployed by government, donors, NGOs, and research centres in the country. The household or banja is indeed a key unit in the social organization of Malawian villages (and towns) but it is not the only one. We have been able, over the course of many years, to document how the sample households interact with other households, especially with those related to them. Households are embedded in broader networks, connected by relations of kinship, marriage, neighbourhood, village, and friendship, as well as through churches and mosques. The matrilineal-matrilocal pattern dominating in the research area means that the key woman in a household is living near sisters, mother's sisters' daughters, and mother's mother's sisters' daughters (cousins of various degrees according to the European system but referred to in Zomba as sisters). Male siblings and cousins usually leave for their wives' village on marriage though some marry within the village, and most have regular contact with their sisters, visiting the natal compounds. They also return home to live between marriages or, as is seen particularly now with the rise of AIDS, during serious sickness. Throughout life, matrikin provide the surest support and the closest ties to a person, though being the main rivals for land, wealth, and status they may also be suspected of witchcraft.

Children move across households for play and for food as well as to give help (a child may be sent to accompany his/her grandmother to the market or to draw water, for example). There is both a positive value given to having a viable, independent household (visually marked by a separate granary, kitchen, basic tools and utensils), and a great deal 
of cooperation among these independent units. The cooperation takes place in routine tasks such as women relatives and friends taking turns to brew and sell beer (so as not to compete for the same clientele) or to process crops, in exchanges of usually small quantities of food, utensils and tools, and particularly in times of crisis or need, such as births, illness, and death. Individual households are also involved in collective activities such as the yearly graveyard cleaning, funerals, memorial feasts, projects of road building or boreholes, and in cases in the chief's court. In short, the ability of a household to be 'independent' depends not only on the key members (key woman, husband, adult children) but also on the supportive relations with other households. While many of these are nearby, some are the households of adult children or siblings who live and work in towns. People, goods and information move between these connected households and may be seen as the 'lifeblood' of social organization in Malawian villages.

The effects of AIDS cannot be understood without recognizing that households are part of larger networks on which they depend and which they, in turn, sustain. ${ }^{\text {xviii }}$ While one cannot underestimate the material losses, let alone the grief, of those directly affected by AIDS, the wider family can be seen as the key provider of care for the sick, the dying and the living survivors, and a bulwark against massive deprivation in this research site. The vast majority of care to the sick, bereaved and orphaned is given by the wider family; existing households within a matrilineal family reorganise themselves in response to the sickness and death of an adult member and to the needs of orphaned children; and land is not left unused because its 'owner' dies but it is given to another member of the matrilineage, first to the heirs of the deceased but if they are too young then to a close relative to use until the heirs are of an age to need the land. 
But this diffused responsibility exerts often considerable cost on individuals and families. Grandmothers find themselves with fewer adult children to rely on, with some adult children returning home sick and dying, and with the task of becoming mothers to their orphaned grandchildren. Sisters and daughters have to take on extra responsibility in providing care to sick relatives (sisters, brothers, parents, and others), and/or to take in orphaned children of the deceased. In households where the mother, father, or both fall sick, school-going daughters and sons miss days of school, some even being forced to drop out entirely, because they have to provide care to their sick parents and/or their parents are unable to raise the fees and other costs for school. Teenage orphans are more likely to drop out of school, even when there is no financial obstacle, and are more likely to marry young. ${ }^{\text {xix }}$

The way in which this population has responded to and is living with the HIV epidemic has to be understood in the context of a densely populated area, where land is short and in huge demand. Therefore, our finding that the extended matrilineal family is able in most cases, so far, to absorb most of the very high costs, material and otherwise, of the epidemic should not be assumed to be 'the' case for all of Malawi, still less for Africa. The central role of women in matrilineal-matrilocal areas (especially in family and land matters) may be most significant, but there is a need for more longitudinal studies of other family systems in Malawi (and other countries). It is essential, too, that these findings be placed within their real timeframe. The phrase 'so far' just used, refers to the fact that many extended matrilineal families are already very stretched, and without improvements in the services to help them increase their income level, their capacity to 
care for increasing numbers of sick and orphans, and to gain more equitable access to medical care, some may find it difficult to maintain their roles as primary caretakers.

First, there is the obvious fact that chronic illness and deaths continue to rise (even if the HIV infection rate, currently $12 \%$ nationally and $18 \%$ in Zomba district, were to level off) which means that individuals, households and families are facing a rising burden in terms of costs in resources and time for caring for the sick, preparing for and attending funerals, taking in orphans, and so forth. Second, many of the caretakers are people, especially women, in their late fifties and older. As these caretakers age, the burdens will also increase for the next age cohort, which has a much higher rate of HIV infection. It is possible, therefore, that the current remarkable ability of matrilineal families to manage much of the impact will be further stretched and undermined.

Moreover, there are cross-household or intra-societal effects at play. The betteroff sample households (those with higher levels of resources and income) have, on average, been more able to absorb the effects of AIDS illness and deaths. But if an increasing proportion of these households lose people, cash and time to AIDS, then not only are the households themselves and their close relatives affected. Their losses have broader implications because these better-off households play important roles in local relations of production, distribution and consumption. It is precisely the better-off households who are the producers of true 'surplus' maize which they store and sell in much bigger quantities than the majority of sample households; they are also the largerscale producers of burley tobacco and other cash crops. Declines in their ability to produce large surpluses will reduce local supplies of maize; and will reduce the likelihood of their hiring people for food in the deficit season (which, while not equitable, 
nevertheless serves as a resource for some of the poorer). Additionally, their reduced overall income level will necessarily cut their expenditures, many of which have been for local products (furniture, beer, mats, baskets, pots) and services (building, well-digging, tailoring, carpentry, bike repair). In short, the socio-economic links between the better-off households and others mean that major losses among the better-off minority do not augur well for the poorer.

The obvious conclusion is that the continuing ability of the extended family to take on responsibility for caring for increasing numbers of sick and dying people and for orphaned children is not guaranteed and requires more effective socio-economic development to improve their access to food, income, and public services.

\section{Lack of extra-family care}

Despite a proliferation of 'community-based' organizations supposed to serve the needs of orphans and HIV-infected/affected individuals and households, the 2006 research in the Zomba villages found that extremely few households with orphans and/or an HIV-related illness or death had received help from such groups. This will be dealt with in a separate paper but the main conclusions are the following. First, the assumption among donors, government and NGOs that care for individuals and families affected by HIV should be based on 'volunteers' is misplaced. It ignores the fact that virtually all care and cooperative effort in the villages is and has always been 'voluntary' and that people are already over-burdened with such efforts.

Second, the way in which voluntarism is tapped - through 'community-based' organizations - is flawed. The (relatively) large funds (mostly around K1.2 million, worth $\$ 10,000$ in 2006) granted to groups are to set up business enterprises intended to provide 
a 'sustainable' source of funds for the services provided. ${ }^{\mathrm{xxx}}$ In no case in the villages was this achieved: virtually all the money and the voluntary effort were consumed with trying to establish and manage the enterprises with little or no resources actually reaching the orphans and others supposed to be helped. Where services were delivered to orphans, they were highly sporadic, often separated by many months as the organisers scrabbled to find money to purchase food and other goods. People suffering from AIDS were even less likely to receive help, though two sample respondents were receiving care and ARV drugs through local hospitals.

Far more families received help from the food distributions in early 2006 (as a response to the shortages after the poor harvest of 2005) and from the government's subsidised fertiliser scheme (that helped produce a bumper harvest in 2006) than from the community-based groups. On the other hand, smaller informal groups, usually spearheaded by older women, some connected to churches, were providing small-scale help to HIV-affected neighbours with sick or orphans to care for, as was found in other parts of Zomba district (S. Carr, personal communication). ${ }^{\text {xxxi }}$

A further problem in current government and NGO responses to the HIV epidemic, which can only be briefly noted here, is that the myopic focus on 'orphans' in the programmes set up to respond to the HIV epidemic in Malawi is a mistake. Certainly, the plight of many orphans requires addressing but the current overwhelming focus on orphans as individuals obscures and displaces the serious needs of the families who take care of orphans and of the individuals and families directly suffering from HIV/AIDS. Some of the over-concentration on orphans as a separate category of victims is driven by exaggerated accounts of homeless orphans; some by the representation in foreign media 
and fund-raising that the main problem of the HIV epidemic is the production of orphans; some by the attractiveness of innocent orphans as draws for raising funds; and some, too, derives from an aversion to dealing with the sexual aspect of the HIV epidemic. Compare Fassin, who says that, 'while the situation of orphans has received huge attention by local authorities, the plight of widows and widowers has not' (2007:245), and that 'childhood is linked to innocence ... [t]he exceptional compassion for AIDS orphans is thus part of the discomfort that ... surrounds the management of the epidemic' (p. 248), while de Waal comments that research evidence 'for the most part' shows that orphans are not 'overwhelming society’s capacity to care for them’ (2006: 83).

\section{CONCLUSION}

Comparing the sample households over a twenty year period reveals that their ability to deal with the effects of the HIV epidemic - increased incidence of chronic, serious illness, deaths, and orphans - depends on prior levels of resources and income and, critically, on the capacity of the wider matrilineal family to help. The vast majority of care is, and always has been, provided by households and the wider families of which they are part. While a few households dissolved in the wake of HIV-related deaths, the children, assets and land were absorbed into other, related households. No young children (those under fifteen) were living alone. Some households were suffering acute economic stress after HIV-related deaths but they were in the minority, and most affected households had managed, with the help of matrilineal relatives, to take on extra burdens and responsibilities and to weather the difficulties. However, these findings must not be misunderstood. The ability of most of the sample households and their wider families to 
avoid disaster does not mean that they are not under strain or that their resilience is automatic and frictionless.

Moreover, there are cross-household or intra-societal effects at play. The majority of families have adult children living and working in towns. Some of these send cash or provide other goods on a regular or periodic basis to their parents (and close relatives) in the villages, while the village-based members often reciprocate by sending maize or by caring for children. Many of those who fall seriously ill in towns return to their natal homes to be cared for in their last months. Hence, some rural families are not only losing sources of (periodic) support from town-based members, but are subject to claims from non-resident members, so making it ever more difficult for the wider matrilineal family to respond to the needs of individual households. In addition, the better-off households in the villages (those with higher levels of resources and income) have, on average, been more able to absorb the effects of AIDS illness and deaths. But if an increasing proportion of these households lose people, cash and time to HIV/AIDS, their losses have broader implications because these better off households play important roles in local relations of production, distribution and consumption.

Fundamentally, most of the strain caused by AIDS illness and death, especially in the medium to longer term, is due to the preexisting and continuing levels of need and poverty at household and family levels and of acute shortages at institutional level. ${ }^{\text {xxii }}$ There is a need to forge a stronger link between HIV/AIDS policy responses and general social and economic policies. In particular, this means to improve people's access to food: in even 'good' harvest years, like 2006, there are still households with insufficient food a few months after harvesting, and in 'poor' to 'bad' years, the numbers of food- 
short people quickly escalate. This has long been a problem in Malawi but the HIV epidemic brings it even more to light: poorly nourished people are more vulnerable to sickness, and sick people without access to sufficient nutrition are less likely to improve. The people in the sample who were known to be HIV-positive and the two who were on anti-retroviral therapy all spoke of their problems in getting 'good' food and of the interactions between powerful drugs and the levels of food intake. ${ }^{\text {xxxiii }}$ Providing access to sufficient food should be more incorporated into health treatment, including that for HIV positive people, as well as into the activities of NGO and 'community' groups. In addition, most of the time, the failure to obtain enough food is not a problem of food supply but of insufficient income to purchase it. Again, the issue is widespread poverty, and the danger of policy priorities being focused too narrowly on the HIV epidemic at the cost of finding ways of raising incomes, improving food security, and providing more effective health care and education.

In severely land-short areas, such as the research area, and one that is near markets with relatively good transport options, the HIV epidemic has so far not been associated with an overall decline in agricultural production due to shortages of labour, nor major shifts in cropping patterns, ${ }^{\text {xxxiv }}$ with the exception of burley tobacco. What the Zomba research, as well as considerable other research, shows is that the consequences of the HIV epidemic tend to intensify whatever patterns of inequality and livelihood stress are already in place. Thus, the effect of HIV on patterns of hunger is to reinforce the problems faced by certain social categories. The effects of the HIV epidemic must be seen as a result of the interaction of the epidemic with the social, economic and political organization of people's lives. It is best to see 'HIV/AIDS ... as a chronic, background 
stress factor' (de Waal 2007: 103) that affects individuals, households, and families in different ways. Such a view, in turn, emphasises the need to avoid separating the HIV epidemic from the existing (though intensified) development problems in specific places. The Zomba study echoes findings of the valiant, if only partially successful, efforts of rural people, including the poor, to live in a time of AIDS while facing considerable difficulties (Watkins 2004, Smith and Watkins 2005) rather than an image of a static, conservative and fatalistic population beset by the HIV epidemic (as depicted by Bryceson et al 2004, Bryceson and Fonseca 2006). ${ }^{\mathrm{xxxv}}$ The overwhelming view that emerges from the research is people's strenuous efforts at 'normalization'. This term has been adopted from other research on HIV to capture the efforts made to incorporate the effects of rising illness and death into the normal round of life, in short, to try to make the abnormal as normal as possible. But normalization cannot be fully successful, precisely because things are abnormal, times are out of joint. For some, the rigours of the present situation escape control and cause considerable distress. Neither is striving for normality easy. It requires more support from routine social and economic policies, in particular a much stronger linkage between responses to the HIV epidemic and social and economic policy designed to increase household income and food security, and improved access to basic services of education and health. 


\section{REFERENCES}

Allen, Tim \& Suzette Heald 2004. 'HIV/AIDS Policy in Africa: What has worked in Uganda and what has failed in Botswana?' Journal of International Development 16: $1141-1154$.

Barnett, T. \& P. Blaikie 1992. AIDS in Africa: its Present and Future Impact. London: Belhaven Press.

Barnett, T. \& A. Whiteside 2002. AIDS in the $21^{\text {st }}$ Century. Disease and Globalization. New York: Palgrave Press.

Baylies, Carolyn 2002. 'The Impact of AIDS on Rural Households in Africa: A Shock like Any Other?’ Development and Change 33, 4: 611-532.

Bryceson, Deborah F. 2006. 'Ganyu casual labour, famine and HIV/AIDS in rural Malawi: causality and casualty’. J. of Modern African Studies 44, 2: 173-202.

Bryceson, Deborah F. \& Jodie Fonseca 2006. 'Risking Death for Survival: Peasant Responses to Hunger and HIV/AIDS in Malawi'. World Development 34, 8: 1654-1666.

Bryceson, D., J. Fonseca \& J. Kadzandira 2004. 'Social Pathways from the HIV/AIDS Deadlock of Disease, Denial and Desperation in Rural Malawi’. Report to Care and RENEWAL-IFPRI.

Chimwaza, A.F. \& S. C. Watkins 2004 'Giving care to people with symptoms of AIDS in rural sub-Saharan Africa.' AIDS CARE 16, 7: 795-807.

De Waal, Alex 2006. AIDS and Power. Why there is no political crisis - yet. London, NY and Cape Town: Zed Books and David Philip in association with IAI. 
2007. 'AIDS, hunger and destitution: theory and evidence for the 'new

variant famines' hypothesis in Africa'. In Stephen Devereux ed. The New Famines: Why Famines Persist in an Era of Globalization. London and New York: Routledge, 90-126.

Dorward, A. \& J. Kydd 2004. 'The Malawi 2002 food crisis: the rural development challenge'. J. of Modern African Studies 42, 3: 343-361.

Drinkwater, Michael, Margaret McEwan \& Fiona Samuels. 2006. The Effects of HIV/AIDS on Agricultural Production Systems in Zambia: A Restudy 1993-2005. IFPRI RENEWAL Report, February 2006.

Ellis, F., M. Kutengule \& A. Nyasulu 2003. 'Livelihoods and rural poverty reduction in Malawi’. World Development 31, 9: 1495-1510.

Fassin, Didier 2007. When Bodies Remember: Experiences and Politics of AIDS in South Africa. Berkeley: University of California Press.

Gillespie, S. \& S. Kadiyala 2006. HIV/AIDS and Food and Nutrition Security. From Evidence to Action. Washington, D.C.: IFPRI.

Grant, Miriam R. \& Andrew D. Palmiere. 2003. 'When Tea is a Luxury: the Economic Impact of HIV/AIDS in Bulawayo, Zimbabwe'. African Studies 62, 2: 213-241.

Helleringer, Stéphane \& Hans-Peter Kohler. 2005. 'Social networks, perceptions of risk, and changing attitudes towards HIV/AIDS: New evidence from a longitudinal study using fixed-effects analysis’. Population Studies 59,3: 265-282.

Interagency Coalition on AIDS and Development (ICAD) 2006. HIV/AIDS, Food Security, and Gender Equality. Report on Conference Sessions,VI International AIDS Conference, Toronto, Canada. 
Kaler, Amy 2004. 'The Moral Lens of Population Control: Condoms and Controversies in Southern Malawi’. Studies in Family Planning 35, 2: 105-115.

Lwanda, John 2003.'The [in]visibility of HIV/AIDS in the Malawi public sphere'. African Journal of AIDS Research 2, 2: 113-126

Mather, David et al 2004. 'A Cross-Country Analysis of Household Responses to Adult Mortality in Rural Sub-Saharan Africa: Implications for HIV/AIDS Mitigation and Rural Development Policies'. MSU International Development Working Paper No. 82, East Lansing, Michigan.

Mtika, Mike Mathambo 2003. 'Family Transfers in a Subsistence Economy and under a High Incidence of HIV/AIDS: the Case of Rural Malawi'. J. Contemporary African Studies 21,1: 69-92.

Mufune, Pempelani 2005. 'Myths about condoms and HIV/AIDS in rural northern Namibia’. International Social Science Journal (Unesco) 57, 186: 675-686.

Murphy, Laura L., Paul Harvey \& Eva Silvestre. 2005. 'How Do We Know What We Know about the Impact of AIDS on Food and Livelihood Insecurity? A Review of Empirical Research from Rural Sub Saharan Africa’. Human Organization 64, 3: $265-275$.

Nyambedha, E. O. \& J. Aagaard-Hansen 2007. 'Practices of Relatedness and the Reinvention of Duol as a Network of Care for Orphans and Widows in Western Kenya’. Africa 77-4: 517-534.

Pfeiffer, James 2004. 'Condom Social Marketing, Pentecostalism, and Structural Adjustment in Mozambique: A Clash of AIDS Prevention Messages.' Medical Anthropological Quarterly 18, 1: 77-103. 
Peters, Pauline E. 1997. 'Against the Odds: Matriliny, Land and Gender in the Shire Highlands of Malawi’. Critique of Anthropology 17, 2: 189-210.

.............. 2002. 'The Limits of Knowledge: Securing Rural Livelihoods in a Situation of Resource Scarcity'. In C. B. Barrett, F. Place and A. A. Aboud, eds. Natural Resources Management in African Agriculture. Understanding and Improving Current Practices. Oxford and New York: CABI Publishing, 35-50.

............... 2006. 'Rural Income and Poverty in a Time of Radical Change in Malawi’. Journal of Development Studies 42, 2: 322-345.

Poulin, M. J. 2006. Sex, Money, and Premarital Partnerships in Southern Malawi. U. Pennyslvania Working Paper.

Probst, Peter 1999. 'Mchape '95 or The Sudden Fame of Billy Goodson Chisupe: Healing, Social Memory and the Enigma of the Public Sphere in Post-Banda Malawi'. Africa 69, 1: 108-137.

Reniers, Georges nd. Marital strategies for regulating exposure to HIV. Ms.

Rödlach, Alexander 2006. Witches, Westerners and HIV: AIDS and Cultures of Blame in Africa. Walnut Creek. CA: Left Coast Press.

Schoepf, Brooke. 2001. 'International AIDS Research in Anthropology: Taking a Critical Perspective on the Crisis’. Annual Reviews in Anthropology 30: 335-361.

Smith, Kirsten P. \& Susan C. Watkins 2005. 'Perceptions of risk and strategies for prevention: responses to HIV/AIDS in rural Malawi'. Social Science and Medicine 60: 649-666. 
Tibaijuka, Anna K. 1997. 'AIDS and Economic Welfare in Peasant Agriculture: Case Studies from Kagabiro Village, Kagera Region, Tanzania’. World Development 25, 6: 963-975.

Watkins, Susan C. 2004. 'Navigating the AIDS Epidemic in Rural Malawi'. Population and Development Review 30, 4: 673-705.

Whiteside, M. 1999. 'Ganyu labour in Malawi and its implications for livelihood security interventions - an analysis of recent literature and implications for poverty alleviation’. London: ODI, ARE Network Paper no. 99.

Whiteside, A, R. Mattes, S. Willan \& R. Manning. 2002. 'Examining HIV/AIDS in Southern Africa Through the Eyes of Ordinary Southern Africans'. Afrobarometer Paper no.21.

Yamano, Takashi \& Thomas Jayne 2004. 'Measuring the impacts of prime-age adult death on rural households in Kenya'. World Development 32, 1: 91-119. 

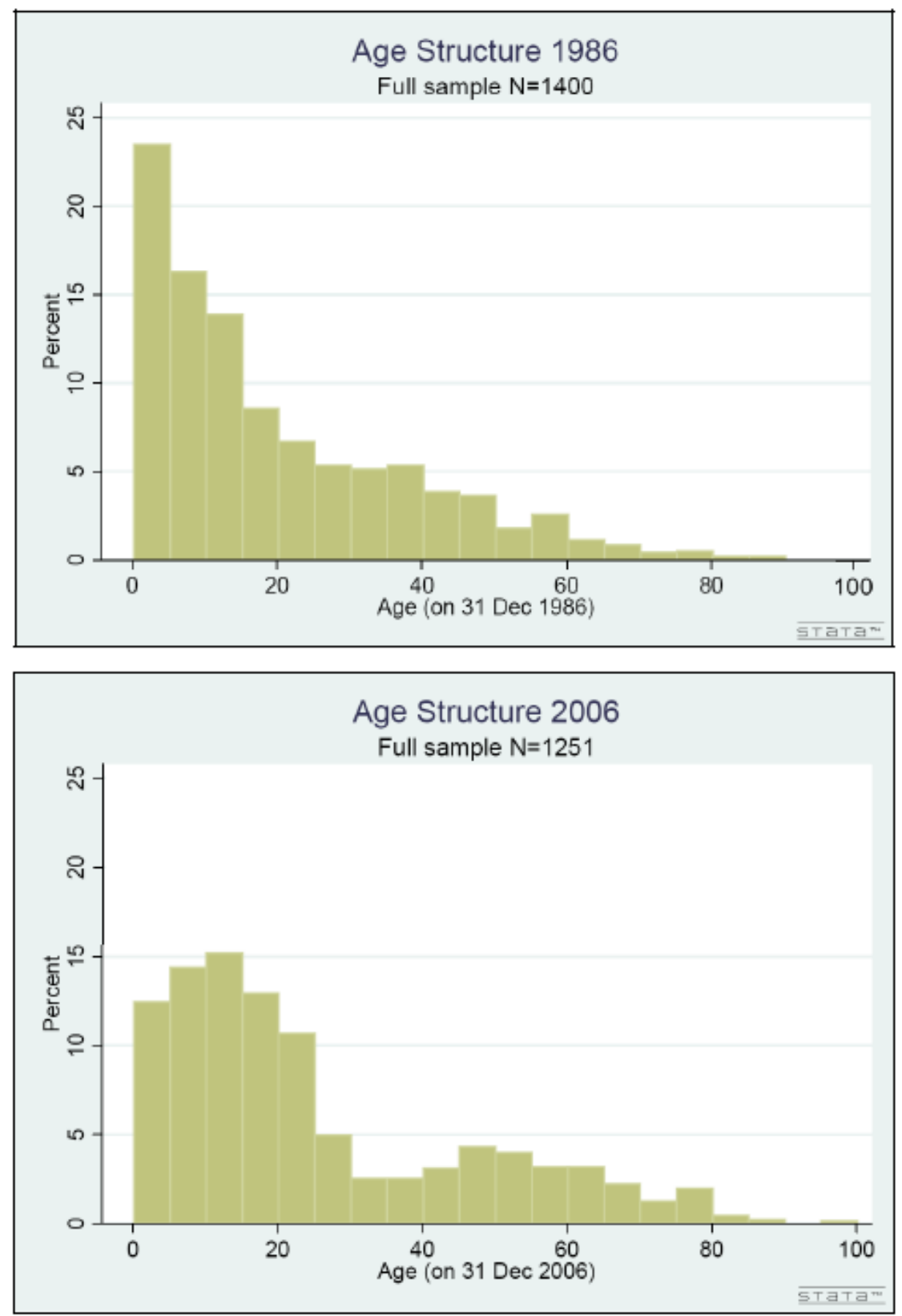

Figures 1-2: Age distribution in sample households, 1986 and 2006

[for page 14]

${ }^{\mathrm{i}}$ The first known cases of infection date from the early 1980s but the force of the epidemic in terms of numbers and public knowledge dates from the early to mid 1990s. 
ii Barnett and Blaikie 1992, Schoepf 2001, Baylies 2002, Barnett and Whiteside 2002, Gillespie and Kadiyala 2006.

iii The 1986-7 study took 12 months, as did the follow-up studies of 1990, 1997, and 2006, with shorter stints in intervening years. In all years, the methods used combined ethnography with repeated questionnaire surveys; research assistants lived full time in the sample villages; Peters lived in a village in 1986, 1990 and 1997, Walker did so in 1990 and 1995, and in 2006, the researchers spent time in the villages from a base in Zomba town.

${ }^{\text {iv }}$ Most used in the research area are matenda a boma (government disease), matenda atsopano or matenda a masiku ano (new disease), matenda omwewa (this disease), mphepo yomweyi (this wind); others include kaondetsa or kaliwondewonde (being very thin), magagawa (mixing or passing something around), mliri (disaster).

${ }^{v}$ His wife who appeared not to be ill visited from time to time. It is usual for very sick people to return home to their natal (matri-) families for care. This incidentally is the answer to a question posed by Chimwaza and Watkins in the paper cited where they were 'puzzled ... by the absence of wives taking care of husbands' in their cases. They wondered if 'our informants considered it normal for wives to care for husbands, and so did not direct us to these situations' (2004: 797). In fact, in their site of Balaka, as in Zomba, the matrilineal kinship norms assume the opposite - that (at least for a seriously ill person) sisters and mothers, not wives, are the best care-givers.

${ }^{\mathrm{vi}}$ Various terms are used such as chiwerewere, chigololo, kuyenda-yenda, while in Malawian English it is common to refer to someone being 'movious'.

${ }^{v i i}$ Lwanda (2003:118) quotes a popular song from the early 1990s that included the phrase 'tizirombo tikukhala m'magazi' (these viruses are living in the blood). The Ministry of Health had translated 'virus' into Chichewa as kachirombo (lit. little animal), later amended to the plural as tizirombo (Probst 1999:118). viii One woman commented that a man who often spoke in public about being HIV-positive as part of the information sessions of an NGO was on ARVs and 'looked fat' so that someone might think she could marry him even though, she added, 'he is finished' (ie. he will die).

${ }^{\text {ix }}$ But U.Penn data also show that people's marital choices now pay more attention to HIV risk (Reniers nd, Poulin 2006).

${ }^{\mathrm{x}}$ National data show that HIV prevalence is higher among high income groups.

${ }^{x i}$ This is discussed in a separate paper (in process).

xii Another study in Malawi reports people accusing the whites of doing so either because they, especially Americans, wish to see Black people destroyed or are tired of giving aid funds, and also accuse health workers in Malawi of being in the anti-population growth group and/or wanting to benefit financially from people seeking medical health and needing to buy coffins (Kaler 2004; for suspicions about condoms see Pfeiffer 2004 on Mozambique, Allen and Heald 2004 on Uganda and Botswana, Mufune 2005 on Namibia, Rodlach 2006 on Zimbabwe, Fassin 2007 on South Africa).

xiii There has been net movement out of the area by individuals and sections of families since 1986 (and probably before).

${ }^{\text {xiv }}$ cf. Whiteside 1999; also Bryceson 2006, though it is important to note that casual agricultural labour (a form of ganyu) is not a leveler (of all to 'deagrarianised' poverty) but an intensifier of inequality - the poorest get caught in the vicious cycle which benefits the better-off.

${ }^{\mathrm{xv}}$ Exceptions are male chiefs who live in their natal villages, and some sons whose families have a great deal of land.

xvi This is common; see Drinkwater et al. 2006, note 9.

xvii Monthly in 1986 and 1990, bimonthly in 1997 and 2006.

xviii Many of these were elderly people. Some were small children and the symptoms of malaria were often mentioned; it is possible, of course, that some of these were HIV+ but our information is even more tentative for these than for adults.

xix These 75 households had 123 such (certain to likely HIV) adult deaths in total.

${ }^{\mathrm{xx}}$ There has been a decrease in burley growing from a high of $80 \%$ of sample households in 1997 to $64 \%$ in 2006, and fewer grow burley on any scale.

${ }^{x x i}$ The increase in sweet potatoes, cassava and pigeon peas over the past 15 years is attributable to burgeoning markets in peri-urban and urban areas, though all are also used for food by growers.

xxii UNDP's Human Development Reports (1993, 2007/8) record a modest improvement in anthropometric scores and more dramatic improvements in child and infant mortality in Malawi. 
xxiii These definitions of 'stress' do not consider non-material (psychological, emotional) distress.

${ }^{x x i v}$ Cf. Chimwaza and Watkins 2004:805: '... most of the patients [were] with the caregivers for less than four months. Once they required continual care, the progression to death appeared rapid.'

${ }^{\mathrm{xxv}}$ In the research villages, as elsewhere in Malawi, the number of funerals has increased and people mention the resulting increase in time spent in attending funerals, something never heard in 1986-1990. While all villagers especially those surrounding the bereaved compound are expected to donate small amounts of money or goods, the major cost of a funeral is borne by the close matrilineal relatives of the dead person, though increasingly church and mosque groups are involved in organizing the funeral. xxvi A JMAS reviewer wondered if this might reflect some level of 'shirking' - it is a question we need to investigate further.

${ }^{x x v i i}$ In the local language this is referred to as ulowoka, and is similar to chitengwa in the Central Region. ${ }^{x x v i i i}$ Cf. ' ...it is not possible to understand the social nature of vulnerability and resilience without an analysis that goes beyond the household level' (Drinkwater et al. 2006:xii).

${ }^{x x i x}$ Despite these tendencies, the sample data showed that $90 \%$ of orphans between the ages of 10 and 15 went to school compared with $83 \%$ for the whole sample of children in that age group.

${ }_{\mathrm{xxx}}$ These funds were allocated per project, were from MASAF and NAC, and channeled through the District Administration. The K1.2million figure was the one most often reported by groups to us.

${ }^{x x x i}$ cf. Similar findings about difficulties faced by people in establishing 'community' businesses funded by donors, and the greater likelihood of small-scale groups being able to help in W. Kenya (Nyambedha and Aagard-Hansen 2007).

xxxii Cf. the higher rating of 'economy' and 'health' than for 'AIDS' as targets for government attention according to Malawian responses to the Afrobarometer surveys for 1999-2000 and 20002-3 (Whiteside et al. 2002).

xxxiii Stephen Lewis stressed the importance of food and nutrition when ARVs are introduced, pointing out that 'treating malnourished people with ARVs can be deadly ... they are six times more likely to die than those who are well-nourished' (1CAD 2006:9).

${ }^{\text {xxxiv }}$ Cf. Tibaijuka 1997, Yamano \& Jayne 2004, Murphy et al 2005, S. Carr for other parts of Malawi, personal communication.

${ }_{\text {xxxv }}$ In their research Helleringer and Kohler found that involvement in social networks in Malawi did not incline 'individuals towards the formation of fatalistic risk perceptions or the adoption of risky behaviour: but allowed them to 'gather information about [AIDS] and to assess their own risk of infection' (2005: 280). 